\title{
Fast delivery delivers mechanism
}

The present
methodology
allows us
to study in
otherwise
inaccessible
detail the
mechanism
by which
nitrogenase
forms $\mathrm{H}_{2}$ from
electrons
provided by
the electrode
and protons
from solvent

Fixation of atmospheric $\mathrm{N}_{2}$ is the first step towards constructing the elaborate biomolecules that all life depends on. Bacterial nitrogenase enzymes mediate $6 \mathrm{H}^{+} / 6 \mathrm{e}^{-}$reduction of $\mathrm{N}_{2}$ to two molecules of $\mathrm{NH}_{3}$. The Mo-dependent system hydrolyses ATP at an $\mathrm{Fe}_{4} \mathrm{~S}_{4}$-containing redox protein, driving electron transfer to a protein catalyst featuring an $\left\{\mathrm{Fe}_{7} \mathrm{MoS}_{9} \mathrm{C}(R\right.$-homocitrate $\left.)\right\}$ cofactor bound to His and Cys residues. The resting-state cofactor $\mathrm{E}_{0}$ undergoes $2 \mathrm{H}^{+} / 2 \mathrm{e}^{-}$reduction to give $\mathrm{E}_{2}(2 \mathrm{H})$, which bears hydridic $\mathrm{Fe}(\mu-\mathrm{H})$ $\mathrm{Fe}$ and protic $\mathrm{Fe}(\mu-\mathrm{SH}) \mathrm{Fe}$ groups. Further $2 \mathrm{H}^{+} / 2 \mathrm{e}^{-}$reduction affords $\mathrm{E}_{4}(4 \mathrm{H})$, a state that must reductively eliminate $\mathrm{H}_{2}$ to produce a lowvalent intermediate that activates $\mathrm{N}_{2}$. Yet, a $\mu-\mathrm{H}^{-}$ligand in $\mathrm{E}_{4}(4 \mathrm{H})$, instead of undergoing reductive elimination with another hydride, can be protonated by a $\mu-\mathrm{SH}^{-}$group to evolve $\mathrm{H}_{2}$ and return $\mathrm{E}_{2}(2 \mathrm{H})$. This competing protonolysis reaction, which can also convert $\mathrm{E}_{2}(2 \mathrm{H})$ to $\mathrm{E}_{0}$, is poorly understood because it is much faster than the overall electron-transfer process. Writing in the Journal of the American Chemical Society, a team led by Lance Seefeldt and Brian Hoffman use small molecules to quickly shuttle electrons from an electrode to the catalyst, allowing them to unravel the mechanism of this important side reaction.

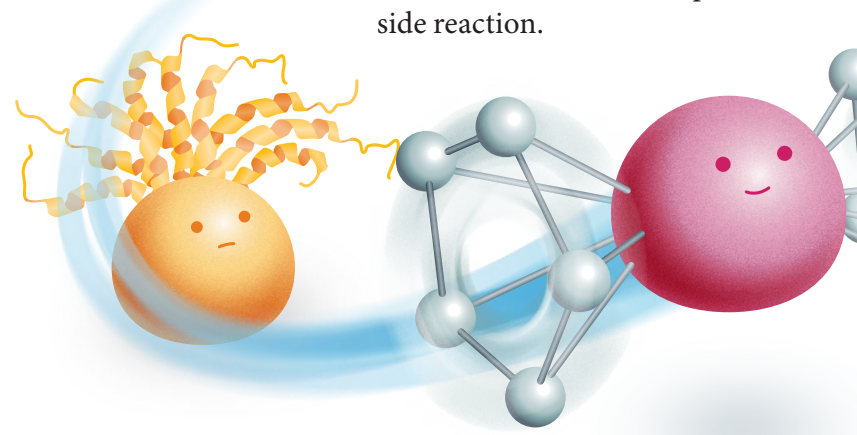

Rachael Tremlett/Macmillan Publishers Limited
A lot needs to happen for each electron to reach the active site for catalysis: the redox protein has to bind to the catalytic protein, whereupon a conformational 'gate' opens to allow electron transfer. This is driven by cleavage of two ATP substrates, after which two phosphates are disposed of. Only then can the redox protein dissociate from the catalyst, dump two ADPs and refuel with two ATPs and an electron. The overall process - in particular, phosphate dissociation cannot happen any faster. "As a result, one cannot at will drive nitrogenase to a desired state, but rather must find other ways to characterize the catalytic mechanism and its intermediates," says Hoffman. Previous work of Seefeldt had shown that the native processes can, in some cases, be replaced by attaching the catalytic protein to an electrode, from which each electron is quickly transferred to $\left[\mathrm{Co}\left(\mathrm{C}_{5} \mathrm{H}_{5}\right)_{2}\right]^{+}$, with the $\left[\mathrm{Co}\left(\mathrm{C}_{5} \mathrm{H}_{5}\right)_{2}\right]$ thus formed reducing the catalytic core. Shuttling by the $\left[\mathrm{Co}\left(\mathrm{C}_{5} \mathrm{H}_{5}\right)_{2}\right]^{+/ 0}$ couple is so fast that electron transfer is no longer rate limiting, and one can now probe the kinetics of chemical steps involved in $\mathrm{H}_{2}$ evolution by protonolysis - a process isolated by starving nitrogenase of $\mathrm{N}_{2}$.

When the team increased the $\mathrm{D}_{2} \mathrm{O}$ mole fraction $(n)$ in the $\mathrm{D}_{2} \mathrm{O} / \mathrm{H}_{2} \mathrm{O}$ containing electrolyte, they observed a linear decrease in the net current quotient $i_{n} / i_{0}$, implicating movement of a single $\mathrm{H}$ or $\mathrm{D}$ nucleus in the rate-limiting step. The kinetic isotope effect $i_{0} / i_{1}$ is 2.7 for catalysis mediated by $\left[\mathrm{Co}\left(\mathrm{C}_{5} \mathrm{H}_{5}\right)_{2}\right]^{+/ 0}$ compared with 1 for the electron transfer itself.
Although the current in this experiment was sensitive to mutations near the active site, the persistent linearity of the $i_{\mathrm{n}} / i_{0}$ versus $n$ 'proton inventory plot' suggests that the mechanism is invariant. Density functional theory calculations indicate why motion of only a single $\mathrm{H}$ or D nucleus controls $\mathrm{H}_{2}$ formation: $\mathrm{H}^{+}$bound to a sulfido ligand moves towards a tightly held, essentially stationary $\mu-\mathrm{H}^{-}$ligand, with S-H cleavage in the transition state resulting in the observed kinetic isotope effect.

Coupling of protic and hydridic $\mathrm{H}$ atoms (or, conversely, $\mathrm{H}_{2}$ heterolysis) across a metal-heteroatom bond is an intuitive and likely step in many homogeneous systems - from hydrogenase enzymes to transfer hydrogenation catalysts. Implementation of the electron inventory approach will allow this idea to be tested. "The present methodology allows us to study in otherwise inaccessible detail the mechanism by which nitrogenase forms $\mathrm{H}_{2}$ from electrons provided by the electrode and protons from solvent," notes Hoffman. Learning about $\mathrm{H}_{2}$ evolution by protonolysis may teach us how nitrogenase curbs this process to do its main job: making $\mathrm{NH}_{3}$. But there is work to do here, as "one issue to address is that the electrode method described here does not yet produce $\mathrm{NH}_{3}$," laments Hoffman. Uncovering this mechanism may help us develop bio-inspired systems that electrocatalytically produce $\mathrm{NH}_{3}$ - for fertilizers or fuels - in an efficient manner.

David Schilter

ORIGINAL ARTICLE Khadka, N. et al. The
mechanism of nitrogenase $\mathrm{H}_{2}$ formation by metal-
hydride protonation probed by mediated
electrocatalysis and H/D isotope effects. J. Am.
Chem. Soc. http://dx.doi.org/10.1021/
jacs.7b07311 (2017)

